\title{
Expansion and Management Implications of Invasive Alien Spartina alterniflora in Yancheng Salt Marshes, China
}

\author{
Chunyue Liư1, Hongxing Jiang², Shuqing Zhang1, Chunrong Li³ ${ }^{3}$ Xin Pan, Jun Lu², \\ Yunqiu Hou ${ }^{2}$ \\ ${ }^{1}$ Northeast Institute of Geography and Agroecology, Chinese Academy of Sciences, Changchun, China \\ ${ }^{2}$ Research Institute of Forest Ecology, Environment and Protection, Key Laboratory of Forest Protection of State \\ Forestry Administration, Chinese Academy of Forestry, Beijing, China \\ ${ }^{3}$ Yancheng National Nature Reserve, Xinyanggang, Sheyang County, Jiangsu, China \\ ${ }^{4}$ School of Electrical \& Information Technology, Changchun Institute of Technology, Changchun, China \\ Email: jianghongxingcaf@163.com
}

Received 23 November 2015; accepted 15 February 2016; published 18 February 2016

Copyright (C) 2016 by authors and Scientific Research Publishing Inc.

This work is licensed under the Creative Commons Attribution International License (CC BY).

http://creativecommons.org/licenses/by/4.0/

CC) (i) Open Access

\begin{abstract}
Improved understanding of the spatial dynamics of invasive plant species is critical for effective land management and control of future invasion. The Yancheng National Nature Reserve (YNNR), an internationally important wetland, has the largest distribution of alien Spartina alterniflora in China. This alien plant was intentionally introduced for erosion prevention and dike protection in China. However, it became an aggressive competitor with native salt marsh plants in the coastal regions in China. High resolution imagery, SPOT-5, was used to map plant communities including invasive species in the south core zone of YNNR with the natural ecosystem of salt marshes in 2003, 2005 and 2008. The fuzzy set assessment method significantly improved the classification accuracies over the conventional error matrix, i.e., from $73.8 \%, 73.5 \%$ and $81.4 \%$ to $91.5 \%, 91.6 \%$ and $93.4 \%$ in 2003, 2005 and 2008, respectively. It shows a great potential for mapping invasive plant species. Phragmites australis and $S$. alterniflora were the most accurately mapped classes, and sparse and dense Suaeda glauca were the least accurately mapped. From 2003 to $2008, S$. alterniflora increased $28.8 \%$ from 1664.1 to 2142.6 ha in area size, and more than 2.5 times from 742 to 2608 patches. The highest increase in patch number occurred within the interval between 2001 and $3000 \mathrm{~m}$ from the eastern baseline. This increase was dominated by small patches with area less than $200 \mathrm{~m}^{2}$. During the study period, the mean spread width was $405 \pm 80.7 \mathrm{~m}$ in the original large patch of area over 200 ha. The eastward/seaward spread was distinctively larger than the westward/landward. The results enhance the understanding of alien plant's invasion patterns and help improve conservation efforts.
\end{abstract} agement Implications of Invasive Alien Spartina alterniflora in Yancheng Salt Marshes, China. Open Journal of Ecology, 6, 113-128. http://dx.doi.org/10.4236/oje.2016.63012 


\section{Keywords}

\section{Spartina alterniflora, SPOT-5, Remote Sensing, Fuzzy Set Assessment, Expansion Characteristics, Management Implications}

\section{Introduction}

Alien invasive species can alter the composition, structure, and functioning of both terrestrial and aquatic ecosystems [1] [2], pose threats to biological diversity, and lead to habitat loss and fragmentation [3]-[7]. Combined with anthropogenic disturbances such as land conversion and climatic change, the expansion of alien species is likely to continue, or even accelerates in the near future [8] [9]. Therefore, the major challenge for land managers, conservationists and ecologists is to determine how to effectively manage non-native plants and preserve native biodiversity. Distribution maps are critical for early detection and rapid response to new invasions [9]-[11], and they also provide support for decision making regarding management and control efforts [12] [13].

Spartina alterniflora (hereafter referred to as S. alterniflora) is a perennial grass native to the Atlantic and Gulf coasts of North America [14]. It was intentionally introduced to Jiangsu coastal wetland for erosion prevention, soil melioration and dyke protection in 1979 [15] [16]. However, the exceptional adaptability and reproductive ability of this species have led to its extensive dispersal along the eastern coast of China from Liaoning Province to Guangxi Province, where it has had a negative impact on native species [17] [18]. In 2003, S. alterniflora was listed as one of top 16 invasive species by State of Environment Protection Agency of China [19]. Subsequently, its invasion and control have been a major challenge and received intense interest from biologists and ecologists in China and abroad [17] [20]-[23].

Since its introduction to the coastal wetland of Jiangsu Province in 1982 [15], S. alterniflora has formed the largest invasion area in China to date [18] [22], particularly in the Yancheng National Nature Reserve (YNNR). The distribution area of S. alterniflora in the YNNR reached 14,491 ha in 2007 [22], accounting for $42 \%$ of the total invasive area in China [18]. The reserve is composed of core, buffer, and experiment zones, with the aim of conserving rare waterbirds and coastal wetland ecosystem. In 2009, the remaining natural wetland only accounted for $11 \%$ of the total area, facing increasing pressure of further loss, degradation and fragmentation due to the land conversion and invasion of S. alterniflora [22]. It is urgent to assess the detailed distribution of S. alterniflora in order to support effective strategies of invasive species control and conserving biodiversity.

Remote sensing technology has been widely used to detect numerous invading species in variety of ecosystems [5] [10] [11] [24] [25]. There are a number of types of remote sensing imagery currently available, acquired by both public and private satellites as well as an array of airborne sources of aerial photos and imagery. Choosing the appropriate remotely sensed data for a study needs to account for the tradeoffs among spatial extent (size of image), spatial resolution (pixel size), spectral resolution (number and range of visible and infra-red bands) and temporal resolution (frequency of data acquisition) [13]. Previously studies mainly used the Lands at TM and ETM+ images to detect the distribution of S. alterniflora at the landscape scale [14] [22] [26]-[29]. Landsat was incapable of identifying detailed expansion characteristics at smaller spatial scales due to low spatial resolution of this imagery, especially in the early infestation stage. Early detection of invasive plants when their spatial extent is small reduces the cost of control and increases the possibility of successful eradication [30].

Fortunately, higher-resolution satellite-based imagery is now commercially available. Quickbird $(0.6 \mathrm{~m})$, IKONOS $(1 \mathrm{~m})$ and SPOT-5 $(2.5 \mathrm{~m})$ with a higher spatial resolution image have been used to map vegetation in different wetland environments, including mangroves and submerged aquatic vegetation [30]-[33]. Traditionally, the classes in thematic maps have been treated as crisp sets, based on the classical set theory. In this formulation, map classes are assumed to be mutually exclusive and exhaustive. This approach limits the ability of thematic maps to represent the continuum of variation found in most landscapes [34]. Fuzzy sets allow more flexibility for treatment of map classes in the accuracy assessment, and consider the magnitude of errors and the frequency of ambiguity in map classes [34].

This study used high resolution SPOT-5 images to derive the distribution maps of S. alterniflora patches in the south core zone of YNNR at $2.5 \mathrm{~m}$ spatial resolution. The YNNR is the largest coastal wetland reserve in 
China [22]. The study area is in natural condition with the exception of S. alterniflora invasion, because it is being managed by the reserve authority and no land reclamation has been allowed to occur. The objectives are threefold:

1) to assess the accuracy of land cover maps based on fuzzy set theory, and map the detailed distribution of $S$. alterniflora patches in YNNR in 2003, 2005 and 2008; 2) to analyze the spatial expansion characteristics of $S$. alterniflora patches of different sizes over the study periods; and 3) to discuss management implications based on the results of temporal and spatial patterns of this alien plant.

\section{Methods}

\subsection{Study Area}

The Yancheng Nature Reserve was established by the Jiangsu provincial government in 1983, and became the YNNR in 1992. According to the China's legal system, the national nature reserve is given the highest protection priority. It is located across five counties in Yancheng City in Jiangsu Province of eastern China (Figure 1(A)). The reserve became a member of North East Asian Crane Site Network in 1996 and East Asian-Australian
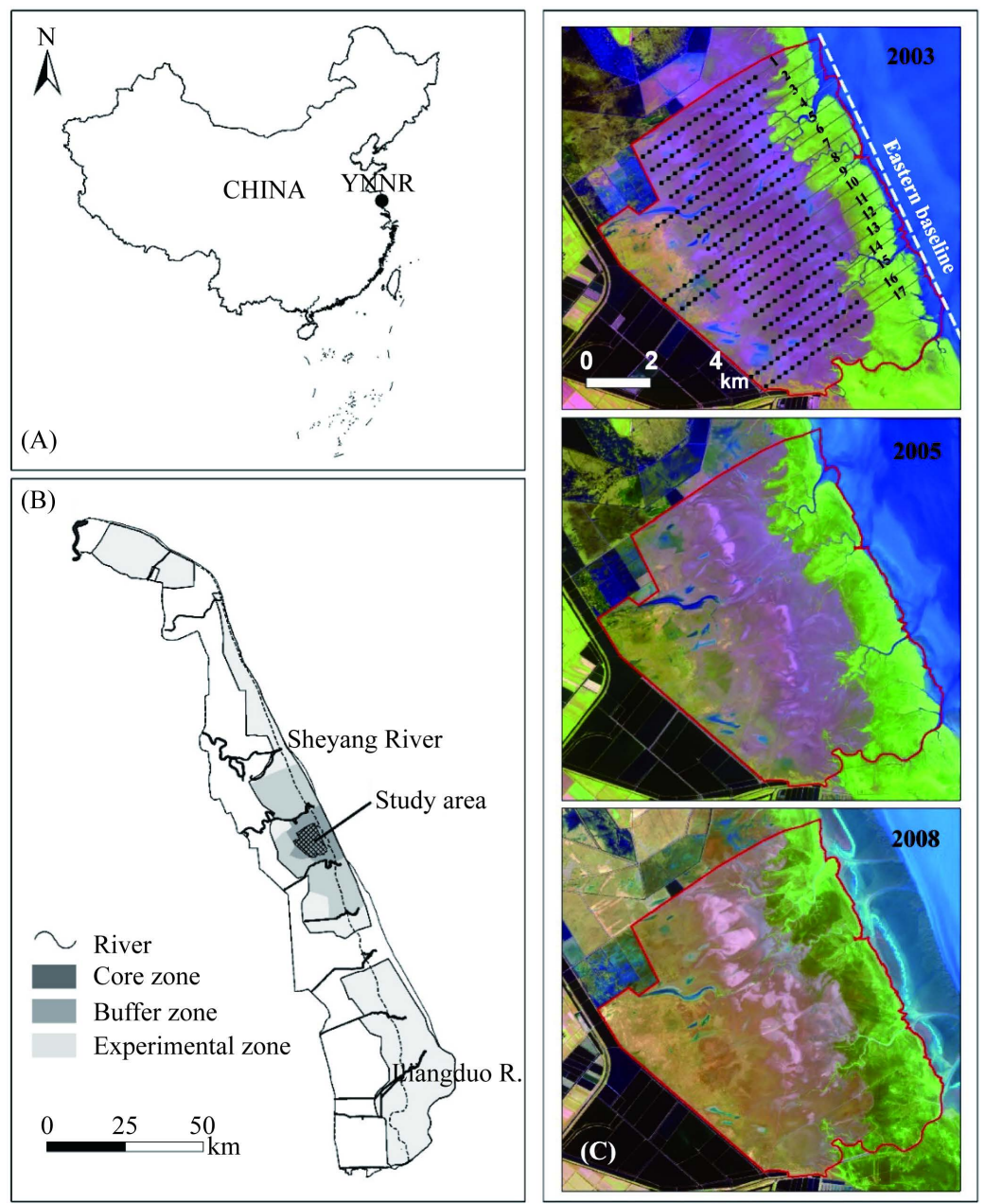

Figure 1. (A) The Yancheng National Nature (YNNR) is located at the center of east coast of China; (B) The study area is located at the south of core zone of YNNR; (C) SPOT-5 images of the study area highlighted by the red boundary (composed of bands 4, 3, and 2 for red, green, and blue) in 2003, 2005 and 2008. The black rhombuses along the transect lines in 2003 image indicate the locations of field samples, which were continued in 2005 and 2008. The gray lines indicate the extension of 17 transect lines. The white dashed line presents the baseline for calculating the number of Spartina alterniflora patches in different distance intervals for each year. 
Shorebird Site Network in 1999, and an internationally important wetland in 2002 [35]. This recognition is a result of its global significance for the breeding, stopover and wintering of migratory waterbirds, especially for the globally threatened species, such as breeding Saunders gull Larus saundersi [36]-[38], wintering Red-crowned crane Grus japonensis [39] [40], and migratory spotted greenshank Tringa guttifer [41].

Salt marshes are the most common habitats in the intertidal zone with S. alterniflora, Suaeda glauca, and Phragmites australis, representing the most common plant communities in the coastal hinterland. In the past two decades, the natural wetlands of YNNR experienced huge losses and fragmentation due to land development and invasion of S. alterniflora [27] [28]. Since 2005, the majority of reclamation was occurred in the community of S. alterniflora, which was distributed in the outer periphery of salt marshes [22]. The reserve authority only has the land ownership in core zone and can manage the habitats not to be developed. The south core zone is this study area $\left(33^{\circ} 27^{\prime} \mathrm{N}-33^{\circ} 40^{\prime} \mathrm{N}, 120^{\circ} 30^{\prime} \mathrm{E}-120^{\circ} 44^{\prime} \mathrm{E}\right)$, where is in natural condition with the exception of $S$. alterniflora invasion (Figure 1(B) and Figure 1(C)).

\subsection{Land Cover Classification Scheme}

Before introduction of S. alterniflora, the native saline vegetation consisted of S. glauca and P. australis. The S. glauca community inhabited the outer periphery of salt marshes and was located in the middle and lower intertidal zones. The P. australis community was mixed with Aeluropus littoralis and Imperatacy cylindrical, and was located in the upper intertidal zone [38]. After its introduction in 1982, this alien plant inhabited the mudflats in the lower intertidal zone in the early infestation stage, and gradually invaded S. glauca and even $P$. australis communities. Therefore, we classified eight land cover types for the study area, which can also be applicable to SPOT-5 imagery resolution (Table 1).

\subsection{Imagery Source}

Three cloud-free SPOT-5 scenes images acquired on 24 October 2003, 31 October 2005 and 7 December 2008 were collected over the southern area of YNNR. Each SPOT-5 scene was purchased with four spectral-band (10-m pixel resolution) and one panchromatic-band (2.5-m pixel resolution) bundles. Pre-processing of digital images was conducted by the commercially available image processing software package ENVI v4.5 [42]. Each image was projected to the Universal Transverse Mercator (UTM) coordinate system, Center Meridian E120, World Geodetic System of 1984 (WGS84), using second-order transformation and nearest neighbor re-sampling, and the pixel size was kept at $2.5 \times 2.5 \mathrm{~m}$. The imagery of 2003 was geometrically registered to the images of 2005 and 2008 in ENVI v4.5 (Research Systems Inc., 2008) using ground control points between the images

\section{Table 1. Land cover classification scheme of the study area.}

\begin{tabular}{|c|c|c|}
\hline No & Land cover types & Remarks \\
\hline 1 & Spartina alterniflora & $\begin{array}{l}\text { Alien invasive plant, is distributed across the whole intertidal salt marshes. The patches with large } \\
\text { area and high density, are not available habitats for waterbirds, except their outer periphery. }\end{array}$ \\
\hline 2 & Sparse Suaeda glauca & $\begin{array}{l}\text { Coverage is lower than } 40 \% \text {, which provides breeding habitats for Saunders's gull, Common Tern, } \\
\text { White-fronted Tern and Kentish Plover and so on [36] [38], and the wintering habitats for } \\
\text { Red-crowned crane [39] [40]. }\end{array}$ \\
\hline 3 & Dense S. glauca & $\begin{array}{l}\text { Coverage is higher than } 40 \% \text {, which provides wintering habitats for Red-crowned crane with } \\
\text { condition of food availability [39] [40]. }\end{array}$ \\
\hline 4 & Phragmites australis & $\begin{array}{l}\text { The dominant plant is } P \text {. australis, mixing with Aeluropus littoralis and Imperatacy cylindrical, } \\
\text { provides breeding habitats for Reed parrotbill, and Great reed warbler and so on [35], and also } \\
\text { wintering habitats for Red-crowned crane [39] [40]. }\end{array}$ \\
\hline 5 & Unvegetated marsh & $\begin{array}{l}\text { Bare mudflat and lower land with open water, which provide feeding habitats for breeding and } \\
\text { wintering waterbirds. }\end{array}$ \\
\hline 6 & Intertidal mudflats & $\begin{array}{l}\text { Mudflat between the outer peripheries of S. alterniflora in } 2003 \text { and 2008, which provides the } \\
\text { feeding habitats in the low tide for migratory waterbirds. }\end{array}$ \\
\hline 7 & Tidal channels and river & $\begin{array}{l}\text { The river only distributes in the south boundary of study area. The channels and river can provide } \\
\text { feeding habitats for egrets, herons and ducks. }\end{array}$ \\
\hline 8 & Road & $\begin{array}{l}\text { Newly constructed motorbike road in salt marshes, which would increase the human disturbances } \\
\text { to waterbirds, and result in the habitat fragmentation. }\end{array}$ \\
\hline
\end{tabular}


after mosaic processing within the same year. The root mean square error was 0.47 pixels, which is about $1.2 \mathrm{~m}$ on the ground.

\subsection{Training Data}

The YNNR land cover maps were produced using computer-assisted classification (Maximum-Likelihood Classification, MLC) of SPOT-5 imagery in ENVI 4.5. Each image was processed separately (i.e, training-datacollection, classification and accuracy-assessment data collection). Thus, no radiometric atmospheric correction or normalization algorithm was needed [10].

The training data were created using the field data collected in late July of 2003, 2005, and 2008. Seventeen transects were established from inland (west) to the sea (east) in 2003 (Figure 1(C)), which were generated by creating a fishnet with $500 \mathrm{~m}$ width using Data Management Tools in ArcToolbox of ArcGIS 9.2 [43]. On each transect, the sampling points were acquired through setting $250 \mathrm{~m}$ Equidistant Points using Convert Features to Points of Feature conversions in XTools Pro in ArcGIS 9.2 (http://www.xtoolspro.com/). The large patch of $S$. alterniflora was too high and dense to access. Accordingly, the sampling data only reached the western periphery of the zone occupied by this alien plant. The coordinates of sampling points were numbered and imported to the portable GARMIN 60CSx for navigation in the field sampling in three years.

As a compromise between the accuracy of the GPS and the pixel size of the satellite images, we used field plots corresponding to four times the minimum pixel size of SPOT-5 images $\left(6.25 \mathrm{~m}^{2}\right.$ multiplied by $\left.4=25 \mathrm{~m}^{2}\right)$, as suggested by [33] and [44]. At each plot, plant identification, plant composition, percent cover, and the coordinates were collected and recorded. We also recorded a minimum of two and, whenever feasible, four GPS points within a plot. An ArcView shape file of field plots was digitized onscreen using the GPS points, and gathered field information under ESRI ArcGIS 9.2 [45].

For long linear features such as tidal channels, roads and S. alterniflora along the channel, there were few training data pixels in sites. The post-classification masks were applied to distinguish the diminutive patches of S. alterniflora by visual interpretation. The linear features (tidal channels and roads) were wide enough to confidently locate on the imagery by interpreters. Therefore, tidal channels and roads were excluded from the accuracy assessment.

\subsection{Accuracy Assessment}

Traditional binary assessment and fuzzy set assessment were used to compare the overall accuracy of land cover classifications. The use of fuzzy sets in map accuracy assessment expands the amount of information that can be obtained regarding the nature, frequency, magnitude, and source of errors in a thematic map [44] [45]. Fuzzy set theory aids in the assessment of maps produced from remotely sensed data by analyzing and quantifying vague, indistinct, or overlapping class memberships, which can produce higher estimation of map accuracy at the species level than the conventional contingency table [44] [46]. Distinct boundaries between land cover classifications seldom exist in nature. Instead, there are often gradations from one cover type to another. Confusion results when a location can legitimately be labeled as more than one cover type. Unlike a binary assessment, fuzzy set analysis allows partial agreement between the reference and mapped cover types, generally on a five-category scale. Additionally, the fuzzy set analysis provides insight into the types of errors that are being made, which is more useful for assessing land cover types that may grade into one another yet must be classified into discrete types by a human observer [46].

To the end, we used the fuzzy-set analysis to develop the land cover maps. Data collection, processing, and interpretation methods, followed [46] and [44]. Each field plot data was scored between 1 and 5 for five land cover types, which include S. alterniflora, sparse S. glauca, dense S. glauca, P. australis and unvegetated marsh. A five-point membership scale ranging from "absolutely incorrect" to "absolutely correct" values was developed: 1 = absolutely incorrect, 2 = understandable but incorrect, 3 = reasonable or acceptable answer, $4=$ good answer, and $5=$ absolutely correct.

Four fuzzy measures (MAX, RIGHT, DIFFERENCE, and MEMBERSHIP) were calculated to assess the map accuracy [34] [44] [46]. The first measure was called "MAX". The matches in the MAX column indicate sites where the highest rating was given to the class assigned in the map (5, absolutely correct or best answer). MAX provided a conservative estimate of accuracy, and the overall accuracy from MAX was identical to that derived from the conventional binary assessment matrix. 
The second measure was called "RIGHT", which accepts matches using any degree of correctness, whose scores were greater than or equal to 3. Clearly, the percentage of matches of RIGHT measure is, by definition, larger than those measured by MAX. RIGHT quantified the frequency of a plant community in the maps whose scores were larger than or equal to 3 .

The third measure, called "DIFFERENCE", is designed to measure the magnitude of errors, and is calculated as the score for the class assigned in the map minus the highest score given to any other class. This function ranges theoretically from -4 to +4 , when using a linguistic scale from 1 to 5 . High positive or negative values indicate the magnitude of a correct or incorrect classification of a field plot, respectively. All sites that are matches using the MAX function have DIFFERENCE values greater than or equal to 0 and all mismatches are negative. For example, if a site was mapped as a certain land cover class, to which the evaluator assigned a score of 1 whereas s/he gave a score of 5 to another land cover class, the DIFFERENCE function takes a value of 1 - 5 $=-4$. For the ideal case, where the mapped category is perfectly right (score $=5$ ) and all other categories are absolutely wrong (score $=1$ ), the DIFFERENCE function yields a 4 .

The last measure, called MEMBERSHIP, indicates the frequency of set membership (match, M) or nonmembership (non-match, $\mathrm{N}$ ) of a land cover class for each field observation. The higher the membership value is the higher the apparent overlap in the differentiating characteristics within and between classification classes.

\subsection{Accuracy Assessment}

Four steps were employed to quantify the spatial expansion characteristics of $S$. alterniflora community. The first is to detect changes in number of S. alterniflora patches and changes in area of S. alterniflora community over the study periods based on different vertical distance to the eastern baseline. The eastern boundary of study area in 2008 was used to create the eastern baseline, which was converted to the points using Feature to Point by ArcGIS 9.2. All points in 2008 were exported to generate a linear asymptote with a slope of -2.1. Using the most eastern boundary point as reference point, the eastern baseline with the same slope generated on-screen to linear shape file under ArcGIS 9.2 (Figure 1(C)). All vegetation including S. alterniflora patches occurred west of the baseline. The vertical distance of the centroid of each S. alterniflora patch to the eastern baseline was calculated by the Near Function Analysis Tools. The patches were divided into five classes. The number of patches within 1000-m intervals from the baseline was calculated: <1001 m, 1001 - 2000 m, 2001 - 3000 m, $3001-4000 \mathrm{~m}$, and $>4000 \mathrm{~m}$.

The second is to detect changes in number and area of S. alterniflora patches between 2003-2005 and 2003-2008. We used the Selected by Location function to identify the spatial location of the 2003 year' patches in 2005 and 2008. Then we calculated the number and area of these matched patches according to the centroid location assignments. Patches present in 2005 and 2008 that were not present in 2003, were treated as newly formed patches.

To evaluate the effects of patch size on expansion characteristics, we compared diminutive patches $\left(<200 \mathrm{~m}^{2}\right.$ area) to large patches ( $>1$ ha area). We also evaluated changes in the number and area of diminutive and large patches among three years. The area of diminutive patch ranged from one times $\left(6.25 \mathrm{~m}^{2}\right)$ to 32 times $\left(200 \mathrm{~m}^{2}\right)$ the pixel size $(2.5 \times 2.5 \mathrm{~m})$. We divided the diminutive patches into two groups: $6.25-100 \mathrm{~m}^{2}$ and $106.25-200$ $\mathrm{m}^{2}$, to detect the number difference between two groups among three years using the paired samples test of SPSS 19.0.

The forth step is to detect the spread characteristics of original large patches (area over 200 ha) among three years, which were almost consecutively distributed as the vegetation belt in the eastern part of study area. We extended the 17 transect lines by edit tools under ArcGIS 9.2, and recorded the geographical coordinates of intersection points between each transect and both edges of large patches for each year. The expansion distance was calculated to detect the spread difference in east/sea and west/inland directions among three years.

\section{Results}

\subsection{Fuzzy Accuracy Assessment}

MAX function values exceeded 73\% in all 3 years, which are the conservational estimates of accuracy (Table 2, Appendix 1 and 2). These accuracies from MAX are identical to that derived from the conventional binary assessment, i.e. the numbers in the "Matches" column. 
Table 2. Fuzzy accuracy tables for 2005 map classification result of the study area.

\begin{tabular}{|c|c|c|c|c|c|c|c|c|c|c|c|c|c|c|c|c|}
\hline \multicolumn{17}{|c|}{ MAX and RIGHT function } \\
\hline \multirow{2}{*}{ Land cover classes } & \multirow{2}{*}{ Sites } & \multirow{2}{*}{$\%$} & \multicolumn{6}{|c|}{ Max (M)—best answers } & \multicolumn{5}{|c|}{ Right (R)—correct } & \multirow{2}{*}{\multicolumn{2}{|c|}{$\begin{array}{l}\text { Improvement } \\
\text { h(R-M) }\end{array}$}} & \multirow{2}{*}{$\%$} \\
\hline & & & Matches & \multicolumn{2}{|c|}{$\%$} & \multicolumn{2}{|c|}{ Mismatches } & $\%$ & \multicolumn{2}{|c|}{ Matches } & \multirow{2}{*}{$\begin{array}{c}\% \\
100.0\end{array}$} & \multirow{2}{*}{$\begin{array}{c}\text { Mismatches } \\
0\end{array}$} & \multirow{2}{*}{$\begin{array}{l}\text { s } \% \\
0.0\end{array}$} & & & \\
\hline S. alterniflora & 18 & 11.6 & 15 & \multicolumn{2}{|c|}{83.3} & \multicolumn{2}{|c|}{3} & 16.7 & \multicolumn{2}{|c|}{18} & & & & \multicolumn{2}{|c|}{3} & 16.7 \\
\hline Sparse S. glauca & 47 & 30.3 & 29 & \multicolumn{2}{|c|}{61.7} & \multicolumn{2}{|c|}{18} & 38.3 & \multicolumn{2}{|c|}{43} & 91.5 & 4 & 8.5 & \multicolumn{2}{|c|}{14} & 29.8 \\
\hline Dense S. glauca & 46 & 29.7 & 39 & \multicolumn{2}{|c|}{84.8} & \multicolumn{2}{|c|}{7} & 15.2 & 43 & & 93.5 & 3 & 6.5 & & & 8.7 \\
\hline P. australis & 17 & 11 & 13 & & 6.5 & 2 & 4 & 23.5 & 14 & & 82.4 & 3 & 17.6 & & & 5.9 \\
\hline Unvegetated marsh & 27 & 17.4 & 18 & & 6.7 & $\mathrm{~s}$ & 9 & 33.3 & 24 & & 88.9 & 3 & 11.1 & & & 22.2 \\
\hline Total & 155 & 100 & 114 & & 3.5 & 4 & 11 & 26.5 & 14 & & 91.6 & 13 & 8.4 & & & 18.1 \\
\hline & & & & & & & DIFFE & ERENC & CE fun & ction & & & & & & \\
\hline L and cover classes & Sites & & & Mism & latches & & & & & & Mat & tches & & Arit & metic & Arithmetic \\
\hline Lanti Cuver Ciasoses & Jites & -4 & -3 & & -2 & - & & 0 & 1 & & 2 & 3 & 4 & mean o & ismatch & mean of match \\
\hline S. alterniflora & 18 & 0 & 0 & & 1 & 2 & 2 & 1 & 1 & & 2 & 2 & 9 & & 22 & 0.72 \\
\hline Sparse $S$. glauca & 47 & 1 & 3 & & 8 & $\epsilon$ & 6 & 0 & 1 & & 5 & 9 & 14 & & 74 & 0.47 \\
\hline Dense S. glauca & 46 & 0 & 3 & & 3 & 1 & 1 & 0 & 7 & & 13 & 8 & 11 & & 35 & 1.20 \\
\hline P. australis & 17 & 2 & 1 & & 0 & 1 & 1 & 4 & 0 & & 4 & 4 & 1 & & .71 & 1.65 \\
\hline Unvegetated marsh & 27 & 0 & 3 & & 2 & 4 & 4 & 1 & 0 & & 8 & 4 & 5 & & 63 & 0.89 \\
\hline Total & 155 & 3 & 10 & & 14 & 1 & 4 & 6 & 9 & & 32 & 27 & 40 & & 54 & 0.92 \\
\hline$\%$ of total & & 1.9 & 6.5 & & 9.0 & 9. & .0 & 3.9 & 5.8 & & 20.6 & 17.4 & 25.8 & & & \\
\hline & & & & & & & MEMB & BERSH & IIP fun & iction & & & & & & \\
\hline & & & 0 & & & 1 & & & 2 & & & 3 & & & 4 & \\
\hline Land cover classes & Sites & $T$ & $M$ & $N$ & $T$ & $M$ & $N$ & $T$ & $M$ & $N$ & $T$ & $M$ & $N$ & $T$ & $M$ & $N$ \\
\hline S. alterniflora & 18 & 0 & 0 & 0 & 6 & 4 & 2 & 10 & 10 & 0 & 9 & 8 & 1 & 3 & 1 & 2 \\
\hline Sparse $S$. glauca & 47 & 0 & 0 & 0 & 20 & 7 & 13 & 22 & 17 & 5 & 20 & 16 & 4 & 2 & 2 & 0 \\
\hline Dense S. glauca & 46 & 0 & 0 & 0 & 23 & 20 & 3 & 20 & 16 & 4 & 19 & 15 & 4 & 0 & 0 & 0 \\
\hline P. australis & 17 & 0 & 0 & 0 & 13 & 10 & 3 & 4 & 3 & 1 & 1 & 1 & 0 & 1 & 1 & 0 \\
\hline Unvegetated marsh & 27 & 0 & 0 & 0 & 14 & 9 & 5 & 13 & 9 & 4 & 6 & 2 & 4 & 1 & 0 & 1 \\
\hline Total & 155 & 0 & 0 & 0 & 76 & 50 & 26 & 69 & 55 & 14 & 55 & 42 & 13 & 7 & 4 & 3 \\
\hline$\%$ of total & & 0.00 & 0.00 & 0.00 & 49.03 & 32.26 & 16.77 & 44.52 & 35.48 & 9.03 & 35.48 & 27.10 & 8.39 & 4.52 & 2.58 & 1.94 \\
\hline
\end{tabular}

$\mathrm{T}=$ Total number of sites in each group; $\mathrm{M}=$ number of matched sites; $\mathrm{N}$ = number of mismatched sites.

Using the less restrictive assessment metric, RIGHT, improved the correct classifications by $17.7 \%$ in 2003 , $18.1 \%$ in 2005 , and $14.4 \%$ in 2008 . However, improvements in individual land cover classifications varied from $0 \%$ to $29.8 \%$ (in the case of sparse S. glauca in 2005). The sparse and dense S. glauca improved very much in comparison with the other land cover classes. MAX values for the alien S. alterniflora indicated $100 \%$ correct classification in 2003 and 2008, thus no improvement in classification was possible for the RIGHT function in this community in those years. In 2005, however, there was a $16.7 \%$ improvement in classification with the RIGHT function.

The results of DIFFERENCE functions were very similar for the mean of matches (4 scores), which were 
$28.1 \%$ in 2003 , $25.8 \%$ in 2005 , and $29.3 \%$ in 2008 , in the field samples, respectively. The maximum mismatches ( -4 scores) occurred in 2003 (3.6\% of the field sites), primarily of a result in classification error for the unvegetated marsh. These field samples were confused with sparse $S$. glauca community, and their spectra were mixed with vegetation as soil background, thus leading to misclassification. The nature of the mismatches indicated that there was little ambiguity or uncertainty in determining the land cover conditions at each plot.

Results for the MEMBERSHIP functions suggested that a small number (14.37\% in 2003, 25.8\% in 2005, and 17.36 in 2008) of field samples are members of Sparse S. glauca and unvegetated marsh, they are distributed close to evenly between matches and non-matches. These results indicated that land cover classifications were clearly defined and showed little confusion to field crews when they were assigning a linguistic score.

\subsection{Changes in Area of Eight Land Cover Classes}

Eight land cover classes were mapped in the study area (Figure 2).

The area of S. alterniflora and P. australis increased by $28.8 \%$ and $47.3 \%$ in $2003-2008$, respectively (Table 3). The annual increase rate of invasive plant in 2003-2005 (6.7\%) is higher than that in 2005-2008 (4.5\%), while the annual increase rate of $P$. australis was less in 2003-2005 (5.5\%) than in 2005-2008 (10.9\%). The sparse $S$. glauca, unvegetated marshes, tidal channels and rivers, and intertidal mudflats decreased in areas in 2003-2008 (Table 3). The dense S. glauca increased by 69.0\% in area in 2003-2005, and decreased in 2005-2008 $(-1.9 \%)$. The overall area in dense S. glauca increased by 65.7\% (728 ha) in 2003-2008 (Table 3). The entire area of intertidal mudflats in 2003 was completely occupied by the S. alterniflora by 2008 (Figure 2 and Table 3).

\subsection{Expansion Characteristics of $S$ alterniflora Patches}

The numbers of S. alterniflora patches increased by 2.5 times from 742 individuals in 2003 to 2608 in 2008, with annual average increase of 373 patches. The number of patches within each 1000-m interval kept increasing

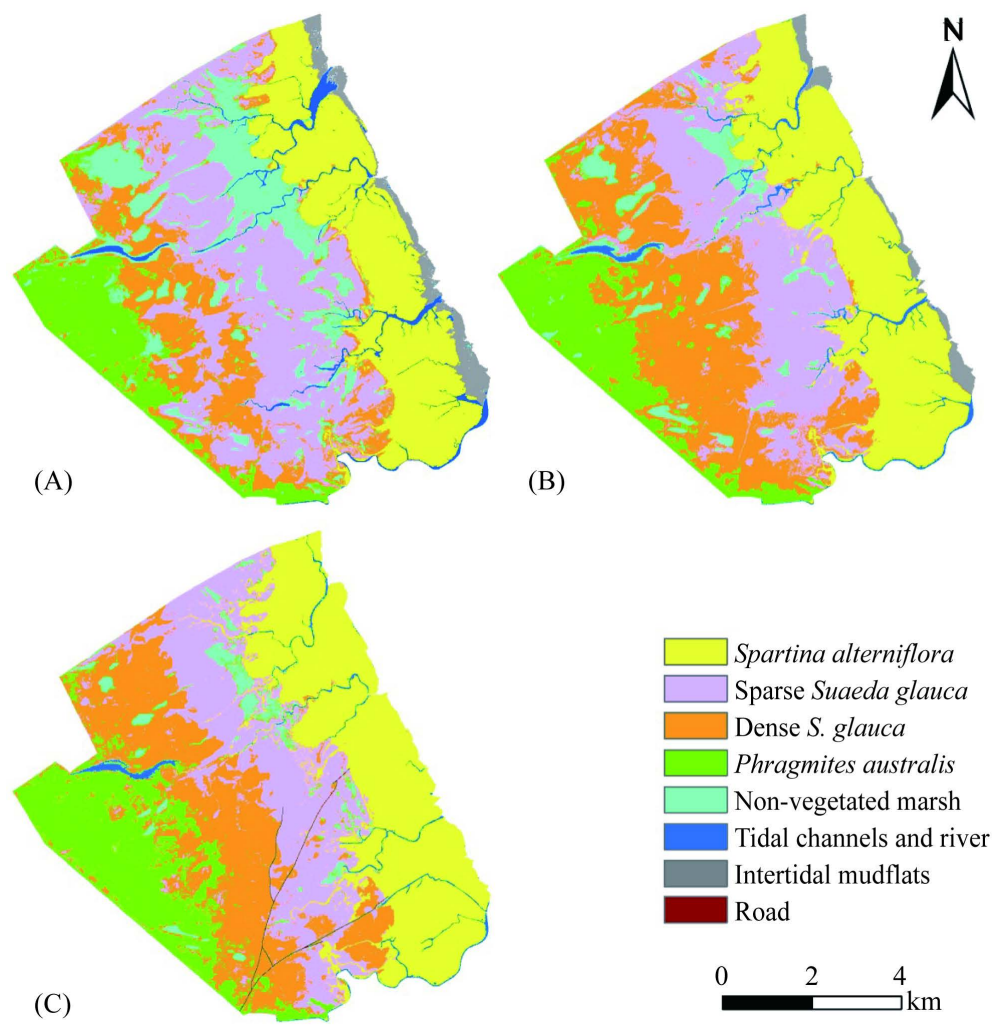

Figure 2. Maps of eight land cover classes of study area generated from SPOT-5 images in 2003 (A), 2005 (B), and 2008 (C). 
from 2003 to 2008, except those in 0 - 1000 m interval between 2003 and 2005 (Figure 3(A)). The maximum increase occurred in the interval from 2001 to $3000 \mathrm{~m}$, which are 422 patches in 2003-2005 and 548 patches in 2005-2008. However, the area of patches increased to the most extent in 0 - $1000 \mathrm{~m}$ interval, which are 126 ha in 2003-2005, and 142 ha in 2005-2008 (Figure 3(B)). The annual average number and area of patches at over 3001-m interval in 2005-2008 increased faster than those in 2003-2005. Contrarily, those at less than 3000-m interval in 2005-2008 increased slower than in 2003-2005. The distance of the most western patch in 2008 (5931 $\mathrm{m})$ was approximately $700 \mathrm{~m}$ far from the most one in 2003 (5247 m).

Specifically, the number of $S$. alterniflora patches in 2003 indicated to be decreasing at each 1000-m interval in the following years, except those at 0 - $1000 \mathrm{~m}$ interval (Figure 4(A)). This was attributed to the large area of patches in this interval and most of them have been connected with each other with the expansion in 2005 and 2008. The number of these patches in 2003 decreased to the most occurred at 2001 - $3000 \mathrm{~m}$ interval, which the area expanded to the most extent at the 1001 - $2000 \mathrm{~m}$ interval, and the second expansion occurred at 2001 $3000 \mathrm{~m}$ interval (Figure 4(B)).

Contrarily, the number of newly formed patches showed increasing at each 1000-m interval between 2005 and 2008 (Figure 5(A)). The number and area increased to the most occurred at 2001 - $3000 \mathrm{~m}$ interval in 2005, which were 680 patches and 1077 ha, respectively. The most increasing of number and area in 2005-2008 appeared at 3001 - $4000 \mathrm{~m}$ interval, which increased by 479 patches in number and by 1025 ha in area (Figure 5(A) and Figure 5(B)). At $0-1000 \mathrm{~m}$ interval, the number and area of new patches formed very slightly, which mainly distributed in the tidal channels.

Table 3. Area and percentage of eight land cover classes of study area in 2003, 2005 and 2008 (the bold numbers presented the overall increase in area of four land covers).

\begin{tabular}{cccccccc}
\hline \multirow{2}{*}{ Land cover class } & \multicolumn{2}{c}{2003} & \multicolumn{2}{c}{2005} & \multicolumn{2}{c}{2008} \\
\cline { 2 - 7 } & Area(ha) & $\%$ & Area(ha) & $\%$ & Area(ha) & \% \\
S. alterniflora & $\mathbf{1 6 6 4 . 1}$ & $\mathbf{2 3 . 9}$ & $\mathbf{1 8 8 8 . 6}$ & $\mathbf{2 7 . 2}$ & $\mathbf{2 1 4 2 . 6}$ & $\mathbf{3 0 . 8}$ \\
Sparse S. glauca & 2241.0 & 32.2 & 1912.7 & 27.5 & 1727.3 & 24.8 \\
Dense S. glauca & $\mathbf{1 1 0 7 . 5}$ & $\mathbf{1 5 . 9}$ & $\mathbf{1 8 7 1 . 7}$ & $\mathbf{2 6 . 9}$ & 1835.6 & 26.4 \\
P. australis & $\mathbf{6 2 9 . 2}$ & $\mathbf{9 . 1}$ & $\mathbf{6 9 8 . 6}$ & $\mathbf{1 0 . 0}$ & $\mathbf{9 2 6 . 5}$ & $\mathbf{1 3 . 3}$ \\
Unvegetated marsh & 894.7 & 12.9 & 305.6 & 4.4 & 189.9 & 2.7 \\
Tidal channels and river & 191.2 & 2.8 & 143.5 & 2.1 & 109.0 & 1.6 \\
Intertidal mudflats & 223.2 & 3.2 & 130.4 & 1.9 & 0.0 & 0.0 \\
Road & 0.00 & 0.0 & 0.00 & 0.0 & $\mathbf{1 9 . 7}$ & $\mathbf{0 . 3}$ \\
Total & 6951.1 & 100.0 & 6951.1 & 100.0 & 6951.1 & 100.0 \\
\hline
\end{tabular}
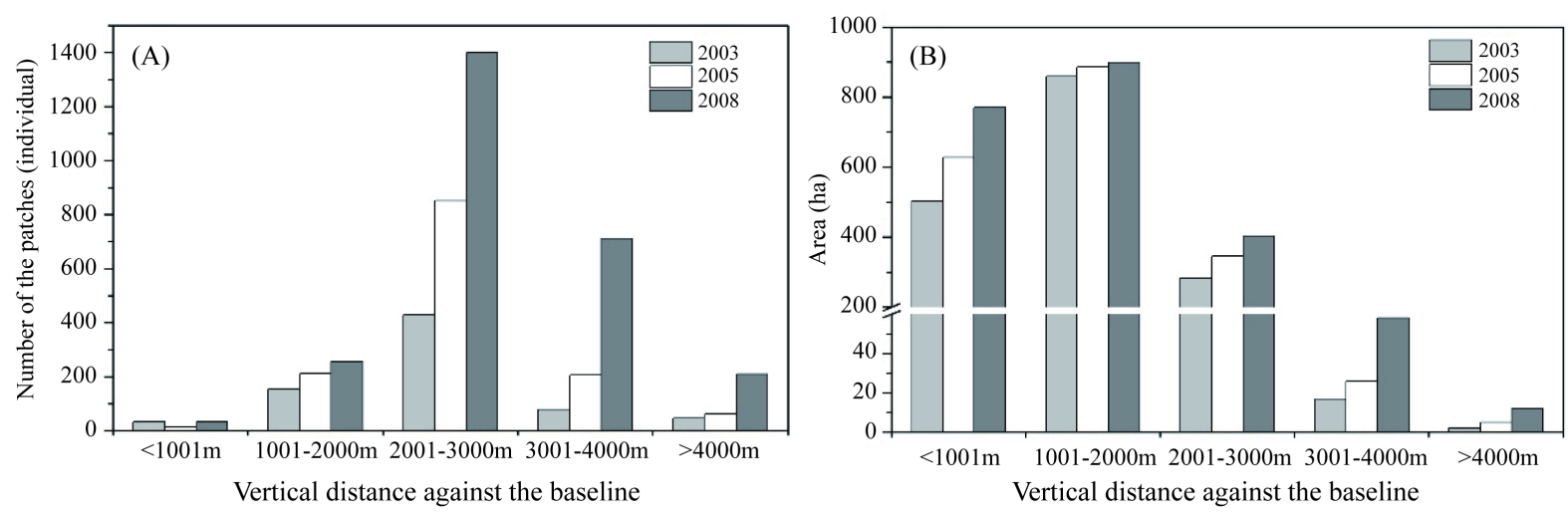

Figure 3. Changes in number of S. alterniflora patches (A) and area of this community (B) at each 1000-m interval against the eastern baseline in 2003, 2005 and 2008. The number of patches was consistent with the number of patch centroids in the corresponding interval belt. 

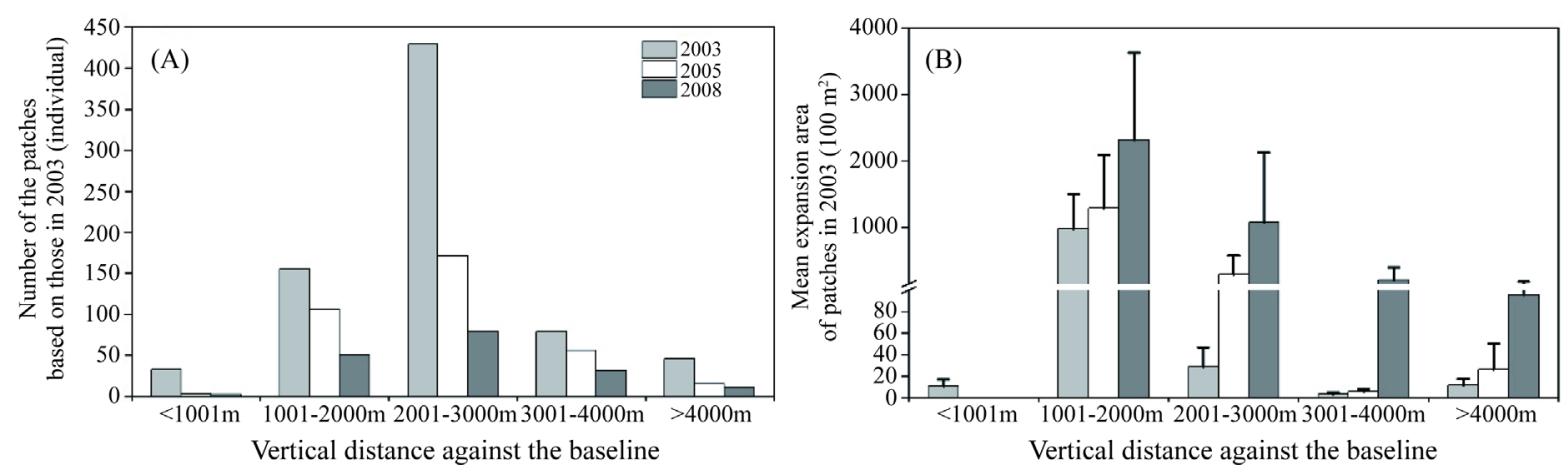

Figure 4. Changes in number (A) and mean expansion area (B) of S. alterniflora patches at each 1000-m interval in 2005 and 2008, which were based on the number and mean area of S. alterniflora patches in 2003.
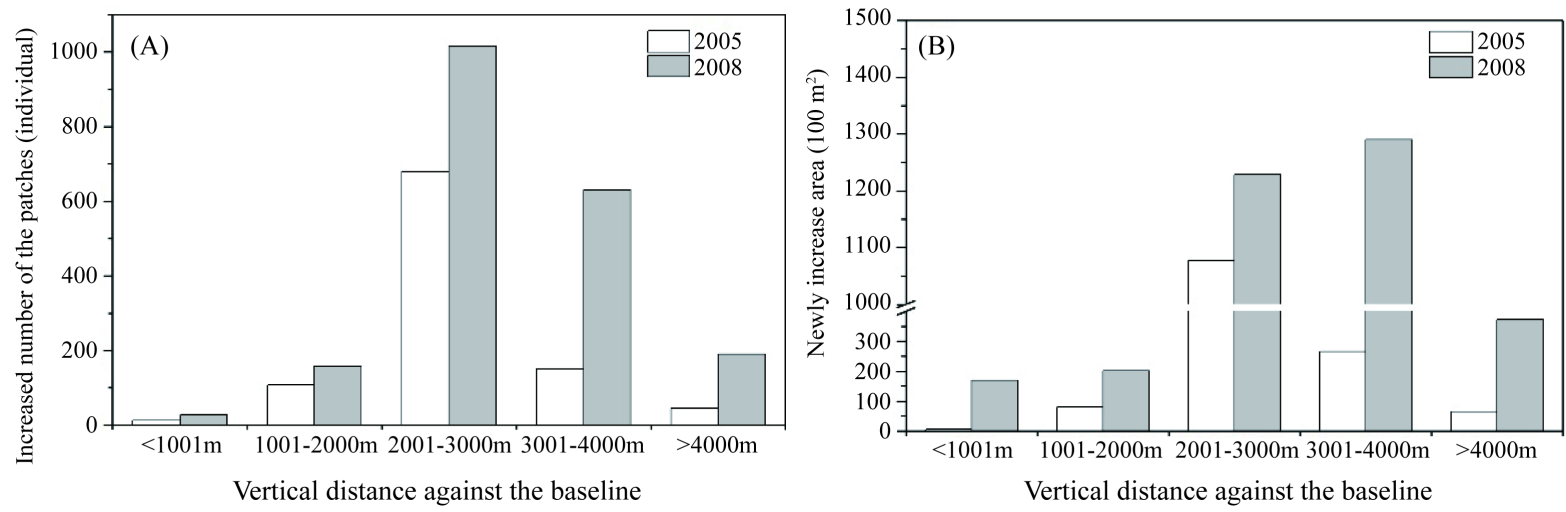

Figure 5. The number (A) and area (B) of S. alterniflora patches newly formed at each 1000-m interval in 2005 and 2008.

\subsection{Changes in Diminutive and Large $S$, alterniflora Patches}

The accumulative number of S. alterniflora patches with area less than $200 \mathrm{~m}^{2}$ accounted for $81.0 \%, 79.7 \%$, and 79.4\% of the total number of S. alterniflora patches in 2003, 2005 and 2008, respectively (Table 4). However, the accumulative area only occupied $0.18 \%, 0.31 \%$ and $0.59 \%$ of the total area in each year. The number of patches with the area less than $100 \mathrm{~m}^{2}$ showed distinctively increasing between 2003, 2005 and 2008. The mean increases in 2003-2005 and 2005-2008 were $23.9 \pm 10.1$, and $50.4 \pm 4.1$ patches, respectively $(n=16, \mathrm{p}<0.05)$. Accordingly, the number of patches with the area between 106.25 and $200 \mathrm{~m}^{2}$, also showed distinctively increasing between three years (5.6 \pm 0.4 in 2003-2005, and $12.1 \pm 1.6$ in 2005-2008). While, the increase range is lower than those in smaller patches.

The numbers of patches with area more than 1 ha were 13 individuals in 2003 (1.75\%), 7 in 2005 (0.52\%), and 16 in $2008(0.61 \%)$, respectively (Table 4). However, the area of these patches accounted for 99.11\%, $98.44 \%$ and $97.30 \%$ of the total area of S. alterniflora community in each year.

\subsection{Spread Characteristics of Original Dominant S. alterniflora Patches}

The numbers of original dominant patches with area over 200 ha were 4 individuals for each year, which accounted for 91.2\%, 98.0\%, and 92.8\% of the total area of S. alterniflora community in 2003, 2005 and 2008, respectively. The mean spread width increased by $405.2 \pm 80.7 \mathrm{~m}$ along 17 transects between 2003 and 2008, including $254.6 \pm 53.2 \mathrm{~m}$ towards east direction and $148.9 \pm 44.7 \mathrm{~m}$ towards west direction. The east spread was significantly larger than that in west direction (118.04 $\pm 54.13, \mathrm{t}=2.181, \mathrm{df}=16, \mathrm{p}=0.044)$.

Mean east spread distance between 2003-2005 was $124.3 \pm 36.5 \mathrm{~m}$, which did not show significant increase in comparison with that $(66.5 \pm 31.0 \mathrm{~m})$ in west direction $(57.8 \pm 47.0 \mathrm{~m}, \mathrm{t}=1.23, \mathrm{df}=16, \mathrm{p}=0.236)$. Mean east spread distance between 2005-2008 was (133.3 $\pm 44.2 \mathrm{~m})$, which also did not indicate significant increase compared with that $(82.9 \pm 22.6 \mathrm{~m})$ in west direction $(47.4 \pm 40.8 \mathrm{~m}, \mathrm{t}=1.161, \mathrm{df}=16, \mathrm{p}=0.263)$ (Figure 6). 
Table 4. Number of patches with area less than $200 \mathrm{~m}^{2}$ and more than 1 ha at each 1000-m interval in 2003, 2005 and 2005.

\begin{tabular}{|c|c|c|c|c|c|c|}
\hline Number of patches & $<1001 \mathrm{~m}$ & $1001-2000 \mathrm{~m}$ & $2001-3000 \mathrm{~m}$ & $3001-4000 m$ & $>4000 \mathrm{~m}$ & Total \\
\hline Year & \multicolumn{6}{|c|}{ Patch area in $6.25-100 \mathrm{~m}^{2}$} \\
\hline 2003 & 27 & 118 & 303 & 55 & 30 & $533(71.80 \%)$ \\
\hline 2005 & 13 & 169 & 537 & 156 & 40 & 915 (67.90\%) \\
\hline 2008 & 28 & 183 & 908 & 460 & 142 & $1721(66.00 \%)$ \\
\hline Year & \multicolumn{6}{|c|}{ Patch area in $106.25-200 \mathrm{~m}^{2}$} \\
\hline 2003 & 0 & 15 & 37 & 10 & 6 & 68 (9.16\%) \\
\hline 2005 & 1 & 15 & 123 & 15 & 4 & $158(11.74 \%)$ \\
\hline 2008 & 0 & 27 & 205 & 96 & 23 & 351 (13.46\%) \\
\hline Year & \multicolumn{6}{|c|}{ Patch area in 1 - 200 ha } \\
\hline 2003 & 1 & 2 & 4 & 1 & 1 & $9(1.21 \%)$ \\
\hline 2005 & 0 & 0 & 2 & 1 & 0 & $3(0.22 \%)$ \\
\hline 2008 & 1 & 0 & 6 & 4 & 1 & $12(0.46 \%)$ \\
\hline Year & \multicolumn{6}{|c|}{ Patch area over 200 ha } \\
\hline 2003 & 0 & 4 & 0 & 0 & 0 & $4(0.54 \% 0$ \\
\hline 2005 & 0 & 3 & 1 & 0 & 0 & $4(0.30 \%)$ \\
\hline 2008 & 0 & 3 & 1 & 0 & 0 & $4(0.15)$ \\
\hline
\end{tabular}

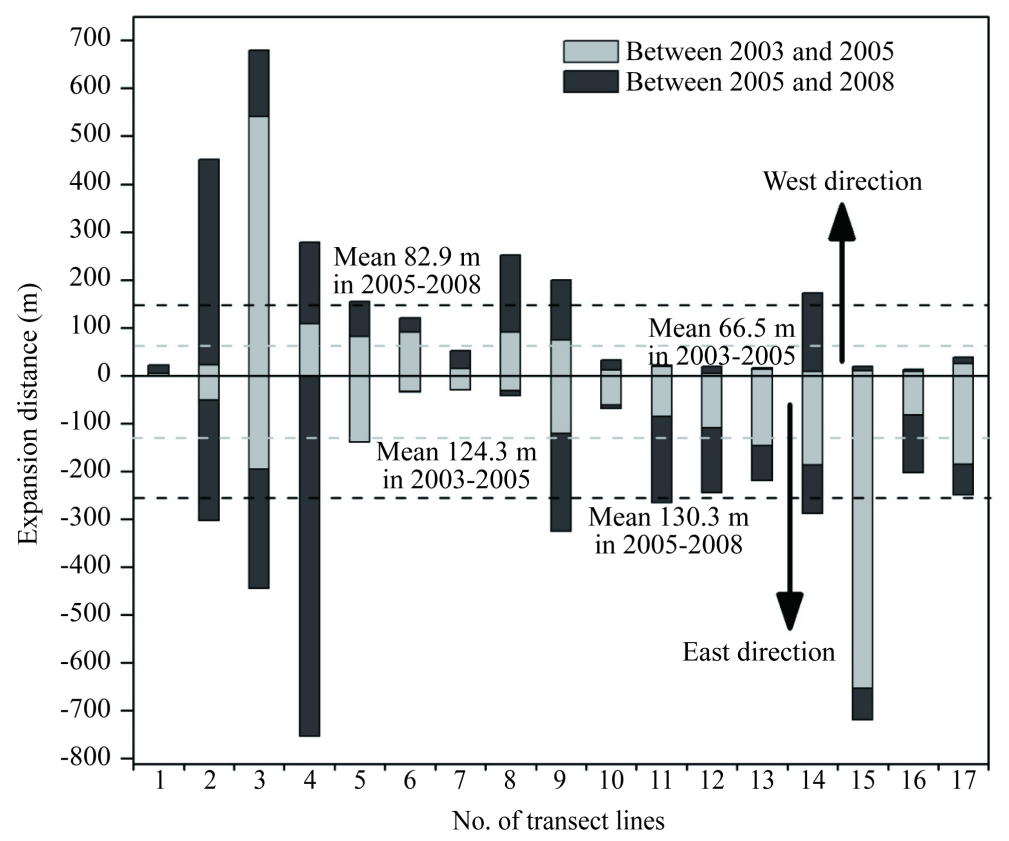

Figure 6. Spread distances of original dominant patches of S. alterniflora along 17 transects between 2003-2005 and 2005-2008, which distributed in the outer periphery of the mudflat. Its mean widths were $1591.8 \pm 103.0 \mathrm{~m}, 1779.9 \pm 117.2$ $\mathrm{m}$, and $1997.0 \pm 122.5 \mathrm{~m}$ in 2003, 2005 and 2008, respectively.

\section{Discussion}

This study further proved the fuzzy accuracy assessment approach combined with abundant field samples can 
significantly improve the map accuracy compared with the conventional binary assessment [34] [44]. The overall accuracies for the land cover maps in 2003, 2005 and 2008 were satisfactory high on a basis of a conventional error matrix (MAX function in fuzzy set assessment), ranging from the lowest 73.5\% in 2005 to the highest 81.4\% in 2008. When the degrees of acceptability of mis-classification are introduced (in the fuzzy assessment approach), the distribution maps were much better, with acceptable classifications in 91.5\% in 2003 and in up to $93.4 \%$ in 2008.

These results are encouraging, given the fact that a simple method (maximum-likelihood classification) was chosen for land cover classification in this study. A number of more sophisticated algorithms are currently available, including several that evaluate and use the spectral local texture of images to improve pixel classification [13] [47]. Based on works done in other contexts, it is likely that this approach can still result in higher classification accuracies in wetlands and marshes. The results can satisfy to recognize invasive process and expansion pattern of exotic S. alterniflora, and to be applied to coastal wetland management.

The classification maps derived from higher resolution satellite data can elaborate the expansion characteristics of S. alterniflora, especially in the early infestation stage when the invasive species has not yet gained dominance. For early detection and rapid response to invasions, higher resolution imagery are therefore more appropriate [44] [48]. In this study, the MAX values for S. alterniflora varied from $83.3 \%$ to $100 \%$ in three years, and a 16.7\% improvement in classification occurred in RIGHT function in 2005. These were largely associated with high spatial resolution of images and small size of field samples (one in 2003, and 18 in 2005 and 2008 ). A combination of high spatial resolution imagery and fuzzy set assessment would effectively improve the overall classification accuracy and early detection abilities of this invasive plant.

The results showed the area of S. alterniflora community increased by 479 ha (28.8\%) from 2003 to 2008 , while the number of patches increased by 2.5 times from 742 individuals in 2003 to 2,608 in 2008, with average annual increase of 373 patches. Specifically, the area of patches increased much larger in 2003-2005 and the number of patches increased much more in 2005-2008. The number of patches with area less than $100 \mathrm{~m}^{2}$ increased by 605 (32.4\% of newly formed patches) and 405 (21.7\%) patches in $2001-3000 \mathrm{~m}$ and $3001-4000 \mathrm{~m}$ intervals, respectively. The newly formed patches with area less than $200 \mathrm{~m}^{2}$ accounted for $67.7 \%(1,264$ patches) of all increased patches. These indicated salt marshes located in $2001-3000$ m interval are the most vulnerable to the invader, and in 3001 - $4000 \mathrm{~m}$ interval is the second.

The S. alterniflora can accrete and hold sediment in intertidal areas that they invade [49]. The rigid, densely packed stems decrease the rate of tidal flow, causing suspended sediment to precipitate, while dense root mats cause sediment accumulation [14] [50]. In New Zealand, rates of sediment accumulation in both S. alterniflora and $S$. townsendii have been reported at around $4 \mathrm{~cm} /$ year, while adjacent open mud showed no change [51].

Tidal water can carry the seeds, root stocks, or other parts of the plants deep into the native salt marshes [52]. S. alterniflora can rapidly settled along the tidal channels and in lower lands of salt marshes. Growth of Spartina spp. along river banks and tidal channels can restrict water flow and cause widening of the floodplain [14]. Introduced S. alterniflora that modifies their physical environment in distinct ways, like through altering substrate characteristics, often has great ecological effects on native communities [52]. The original dominant S. alterniflora patches with area over 200 ha covered over 90\% of total invasive area for each year in the eastern vegetation belt. The mean eastern spread width (254.6 $\pm 53.2 \mathrm{~m})$ was distinctively larger than that in western direction $(148.9 \pm 44.7 \mathrm{~m})$. This indicated that this alien plant invaded mudflats more effective than salt marshes. Its invasion of open mud in the intertidal salt marshes will affect availability of open-mud shorebird feeding areas there [53] [54].

In this study, sparse $S$. glauca kept shrinking in the study period, and dense S. glauca showed increasing in the first stage and shrinking afterwards. S. alterniflora outcompeted S. glauca due to changes in growth conditions [50] [55]. The expansion of S. alterniflora reduced the area of native saline S. glauca, which is the important habitats for globally vulnerable Larus saundersi [36] [38] and endangered G. japonensis [39] [40]. The degradation and shrinking of native salt marshes may cause a decline in numbers of birds and eventually decrease local bird diversity. Our previous study indicated that the degradation of breeding habitats would continue, and suitable breeding habitats for L. saundersi would disappear by 2018 [38].

\section{Management Implications}

The ecological impacts of S. alterniflora invasion have been documented in previously numerous studies, and 
recognized worldwide [14] [21] [22] [52] [54]-[57]. In this study area, introduced S. alterniflora has clear negative effects on native $S$. glauca and $P$. australis communities, and potentially negative effect on invertebrate communities, and eventually affects the local biodiversity and coastal ecosystem integrity [27] [36] [38] [40] [49] [58]. A major issue is how much human resources should be expended in an effort to eliminate present invasions and prevent future invasion.

A number of different strategies have been used to control the invasion of S. alterniflora, including physical, chemical, biological or integrated methods [59]. There have been large variations in its effectiveness ranging from no effect to complete elimination.

Based on our findings related to the specific expansion characteristics of S. alterniflora, combining with its biology, ecology and management in published literatures, we recommend the following management proposals targeting to conserve globally threatened waterbirds and coastal ecosystem.

1) Considering the $S$. alterniflora spread along the tidal channels in the study area, it is recommended to dredge the channels in some appropriate way to ensure that the tide currents can flood the saltmarshes regularly. The tide currents can also swash the dead stems of S. glauca plant to keep low plant coverage and density. These would provide suitable habitats for nesting and feeding by waterbirds [38].

2) For the small patches with area less than $200 \mathrm{~m}^{2}$ in 2001 - $4000 \mathrm{~m}$ vertical interval, the mowing combined with the herbicides would be suitable to maintain the growth of native saline plant. [58] concluded that the most effective method Spartina control technique used in Washington combines a single mowing followed by Rodeo application once its growth reaches $30-45 \mathrm{~cm}$ in height or in the early infestation. [59] illustrated mowing at early florescence is more efficient for controlling S. alterniflora. From a management point of view, each control method has its optimal treatment timing in relation to the phenology of the target plant. However, the effectiveness of different herbicides appears to be highly variable. The use of herbicides could also have deleterious impacts on native flora, and lead to other biological changes within a system. The opportunity also poses great challenge for decision-makers on how to manage this risk.

3) For the original large and dominated patches in the eastern vegetation belt, it is recommended to apply the waterlogging together with mowing. Water irrigation has been used as a means to control S. alterniflora in the marshes and estuaries [17] [60], and even S. alterniflora can survive by respiring aerobically and anaerobically [61]. [62] concluded that waterlogging with water depth less than $50 \mathrm{~cm}$ could promote the growth of $S$. alterniflora, while waterlogging with water depth more than $50 \mathrm{~cm}$ could effectively inhibit the vegetative growth and sexual reproduction, being an effective water depth for controlling the expansion of S. alterniflora.

Managing invaded ecosystems is a great challenge for managers and conservationists, especially in the face of scientific uncertainty and ecological stochasticity [63]. The existing methods for control of S. alterniflora are also uncertain to some extent, and require long-term planning, monitoring and financing. Therefore, it is important to conduct the demonstrations at the first stage to avoid the huge loss of time, money and effort.

\section{Acknowledgements}

This study was supported by the National Natural Science Foundation of China (No. 41201431 and No. 31372226). We thank Yancheng National Nature Reserve for giving us permission to conduct this study. We would like to thank Mr. Wang Hui, Sun Guorong, and Liu Xiaoyun for their involvement in the field works for several years. We also thank the anonymous reviewers for their comments on an earlier version of this manuscript.

\section{References}

[1] Parker, I.M., Simberloff, D., Lonsdale, W.M., Goodell, K., Wonham, M., Kareiva, P.M., Williamson, M.H., Holle, B.V., Moyle, P.B. and Goldwasser, L. (1999) Impact: Toward a Framework for Understanding the Ecological Effects of Invaders. Biological Invasions, 1, 3-19. http://dx.doi.org/10.1023/A:1010034312781

[2] Asner, G.P., Knapp, D.E., Kennedy-Bowdoin, T., Jones, M.O., Martin, R.E., Boardman, J. and Hughes, R.F. (2008) Invasive Species Detection in Hawaiian Rainforests Using Airborne Imaging Spectroscopy and LiDAR. Remote Sensing of Environment, 112, 1942-1955. http://dx.doi.org/10.1016/j.rse.2007.11.016

[3] Pimm, S.L. and Gilpin, M.E. (1989) Theoretical Issues in Conservation Biology. In: Roughgarden, J., May, R.M. and Levin, S.A., Eds., Perspectives in Ecological Theory, Princeton University Press, Princeton, 287-305. http://dx.doi.org/10.1515/9781400860180.287 
[4] Scott, J.M. and Wilcove, D.S. (1998) Improving the Future for Endangered Species. Bioscience, 48, 579-580. http://dx.doi.org/10.2307/1313414

[5] Underwood, E.C., Mulitsch, M.J., Greenberg, J.A., Whiting, M.L., Ustin, S.L. and Kefauver, S.C. (2006) Mapping Invasive Aquatic Vegetation in the Sacramento-San Joaquin Delta Using Hyperspectral Imagery. Environmental Monitoring and Assessment, 121, 47-64. http://dx.doi.org/10.1007/s10661-005-9106-4

[6] Powell, K.I., Chase, J.M. and Knight, T.M. (2011) A Synthesis of Plant Invasion Effects on Biodiversity Across Spatial Scales. American Journal of Botany, 98, 539-548. http://dx.doi.org/10.3732/ajb.1000402

[7] Pyšek, P., Jarošík, V., Hulme, P.E., Pergl, J., Hejda, M., Schaffener, U. and Vilà, M. (2012) A Global Assessment of Invasive Plant Impacts on Resident Species, Communities and Ecosystems: The Interaction of Impact Measures, Invading Species’ Traits and Environment. Global Change Biology, 18, 1725-1737. http://dx.doi.org/10.1111/j.1365-2486.2011.02636.x

[8] Zedler, P.H. and Scheid, G.A. (1988) Invasion of Carpobrotus edulis and Salix lasiolepis after Fire in a Coastal Chaparral Site in Santa Barbara County, California. Madrono, 35, 196-201.

[9] Simpson, M. and Prots, B. (2013) Predicting the Distribution of Invasive Plants in the Ukrainian Carpathisans under Climatic Change and Intensification of Anthropogenic Disturbances: Implications for Biodiversity Conservation. Environmental Conservation, 40, 167-181. http://dx.doi.org/10.1017/S037689291200032X

[10] Lass, L.W., Prather, T.S., Glenn, N.F., Weber, K.T., Mundt, J.T. and Pettingill, J. (2005) A Review of Remote Sensing of Invasive Weeds and Example of the Early Detection of Spotted Knapweed (Centaurea maculosa) and Babysbreath (Gypsophila paniculata) with a Hyperspectral Sensor. Weed Science, 53, 242-251. http://dx.doi.org/10.1614/WS-04-044R2

[11] Huang, C. and Asner, G.P. (2009) Applications of Remote Sensing to Alien Invasive Plant Studies. Sensors, 9, 48694889. http://dx.doi.org/10.3390/s90604869

[12] Bradley, B.A. and Mustard, J.F. (2006) Characterizing the Landscape Dynamics of an Invasive Plant and Risk of Invasion Using Remote Sensing. Ecological Applications, 16, 1132-1147. http://dx.doi.org/10.1890/1051-0761(2006)016[1132:CTLDOA]2.0.CO;2

[13] Bradley, B.A. (2014) Remote Detection of Invasive Plants: A Review of Spectral, Textural and Phenological Approaches. Biological Invasions, 16, 1411-1425. http://dx.doi.org/10.1007/s10530-013-0578-9

[14] Daehler, C.C. and Strong, D.R. (1996) Status, Prediction and Prevention of Introduced Cordgrass Spartina spp. Invasions in Pacific Estuaries, USA. Biological Conservation, 78, 51-58. http://dx.doi.org/10.1016/0006-3207(96)00017-1

[15] Zhong, C., Zhou, R. and Zhou, H. (1985) Study on the Introduction and Cultivation of Spartina alterniflora and Its Effects of Saline Soil Amelioration in China. Journal of Nanjing University, 40, 42-82.

[16] Qin, P. and Zhong, C. (1992) Applied Studies on Spartina. Ocean Press, Beijing.

[17] An, S., Gu, B., Zhou, C., Wang, Z., Deng, Z., Zhi, Y., Li, H., Chen, L., Yu, D. and Liu, Y. (2007) Spartina Invasion in China: Implications for Invasive Species Management and Future Research. Weed Research, 47, 183-191. http://dx.doi.org/10.1111/j.1365-3180.2007.00559.x

[18] Zuo, P., Zhao, S., Liu, C., Wang, C. and Liang, Y. (2012) Distribution of Spartina spp. along China’s Coast. Ecological Engineering, 40, 160-166. http://dx.doi.org/10.1016/j.ecoleng.2011.12.014

[19] Wang, Q., An, S., Ma, Z., Zhao, B., Chen, J. and Li, B. (2006) Invasive Spartina alterniflora: Biology, Ecology and Management. Acta Phytotaxonomica Sinica, 44, 559-588. http://dx.doi.org/10.1360/aps06044

[20] Thomas, M.B. and Reid, A.M. (2007) Are Exotic Natural Enemies an Effective Way of Controlling Invasive Plants? Trends in Ecology \& Evolution, 22, 447-453. http://dx.doi.org/10.1016/j.tree.2007.03.003

[21] Chen, Z., Guo, L., Jin, B., Wu, J. and Zheng, G. (2009) Effect of the Exotic Plant Spartina alterniflora on Macrobenthos Communities in Salt Marshes of the Yangtze River Estuary, China. Estuarine Coastal and Shelf Science, 82, 265272. http://dx.doi.org/10.1016/j.ecss.2009.01.014

[22] Liu, C., Zhang, S., Jiang, H. and Wang, H. (2009) Spatiotemporal Dynamics and Landscape Pattern of Alien Species Spartina alterniflora in Yancheng Coastal Wetlands of Jiangsu Province, China. Chinese Journal of Applied Ecology, 20, 901-908.

[23] Wan, H., Wang, Q., Jiang, D., Fu, J., Yang, Y. and Liu, X. (2014) Monitoring the Invasion of Spartina alterniflora Using Very High Resolution Unmanned Aerial Vehicle Imagery in Beihai, Guangxi (China). The Scientific World Journal, 2014, 1-7. http://dx.doi.org/10.1155/2014/638296

[24] Everitt, J.H., Escobar, D.E., Alaniz, M.A., Davis, M.R. and Richerson, J.V. (1996) Using Spatial Information Technologies to Map Chinese Tamarisk (Tamarix chinensis) Infestations. Weed Science, 44, 194-201.

[25] He, K.S., Rocchini, D., Neteler, M. and Nagendra, H. (2011) Benefits of Hyperspectural Remote Sensing for Tracking Plant Invasions. Diversity and Distributions, 17, 381-392. 
[26] Shen, Y., Liu, Y. and Chen, Q. (2002) Analysis of the Expanding Process of the Spartina alterniflora loisel Salt Marsh on Jiangsu Province Coast by Remote Sensing. Journal of Plant Resources and Environment, 11, 33-38. http://dx.doi.org/10.1016/j.proenv.2011.09.385

[27] Liu, Y., Zhang, R. and Li, M. (2004) Approach on the Dynamic Change and Influence Factors of Spartina alterniflora loisel Salt Marsh along the Coast of the Jiangsu Province. Marine Geology Letters, 20, 18-21.

[28] Zhang, R., Shen, Y., Lu, L., Yan, S., Wang, Y., Li, J. and Zhang, Z. (2005) Formation of Spartina alterniflora Salt Marsh on Jiangsu Coast China. Oceanologia et Limnologia Sinica, 36, 358-365.

[29] Rejmánek, M. and Pitcairn, M.J. (2002) When Is Eradication of Exotic Pest Plants a Realistic Goal? In: Veitch, C.R. and Clout, M.N., Eds., Proceedings of the International Conference on Eradication of Island Invasive Species, IUCN SSC Invasive Species Specialist Group, Gland, 249-253.

[30] Wang, L., Sousa, W.P., Gong, P. and Biging, G.S. (2004) Comparison of IKONOS and Quickbird Images for Mapping Mangrove Species on the Caribbean Coast of Panama. Remote Sensing of Environment, 91, 432-440. http://dx.doi.org/10.1016/j.rse.2004.04.005

[31] Rocchini, D., Butini, S.A. and Chiarucci, A. (2005) Maximizing Plant Species Inventory Efficiency by Means of Remotely Sensed Spectral Distances. Global Ecology and Biogeography, 14, 431-437. http://dx.doi.org/10.1111/j.1466-822x.2005.00169.x

[32] Wolter, P.T., Johnston, C.A. and Niemi, G.J. (2005) Mapping Submerged Aquatic Vegetation in the US Great Lakes Using Quickbird Satellite Data. International Journal of Remote Sensing, 26, 5255-5274. http://dx.doi.org/10.1080/01431160500219208

[33] Poulin, B., Davranche, A. and Lefebvre, G. (2010) Ecological Assessment of Phragmites australis Wetlands Using Multi-Season SPOT-5 Scenes. Remote Sensing of Environment, 114, 1602-1609. http://dx.doi.org/10.1016/j.rse.2010.02.014

[34] Woodcock, C.E. and Gopal, S. (2000) Fuzzy Set Theory and Thematic Maps: Accuracy Assessment and Area Estimation. International Journal of Geographical Information Science, 14, 153-172. http://dx.doi.org/10.1080/136588100240895

[35] Nanjing Institute of Environmental Sciences of Ministry of Environment Protection of China, Nanjing Normal University, Management Bureau of Yancheng National Nature Reserve (2005) Master Plan of Yancheng National Nature Reserve.

[36] Jiang, H., Hou, Y., Chu, G., Qian, F., Wang, H., Zhang, G. and Zheng, G. (2010) Breeding Population Dynamics and Habitat Transition of Saunders's Gull Larus saundersi in Yancheng National Nature Reserve, China. Bird Conservation International, 20, 13-24. http://dx.doi.org/10.1017/S0959270910000055

[37] Liu, C., Zhang, S., Jiang, H., Li, X., Na, X. and Wen, Z. (2009) Remote Sensing Monitoring on Dynamic of Nesting Habitat of Saunder's Gull Larus saundersi. Acta Ecologica Sinica, 29, 4298-4294.

[38] Liu, C., Jiang, H., Hou, Y., Zhang, S., Su, L., Li, X., Pan, X. and Wen, Z.F. (2010) Habitat Changes for Breeding Waterbirds in Yancheng National Nature Reserve, China: A Remote Sensing Study. Wetlands, 30, 879-888. http://dx.doi.org/10.1007/s13157-010-0070-6

[39] Ma, Z., Wang, Y., Gan, X., Li, B., Cai, Y. and Chen, J. (2009) Waterbird Population Changes in the Wetlands at Chongming Dongtan in the Yangtze River Estuary, China. Environmental Management, 43, 1187-1200. http://dx.doi.org/10.1007/s00267-008-9247-7

[40] Liu, C., Jiang, H., Zhang, S., Li, C., Hou, Y. and Qian, F. (2013) Multi-Scale Analysis to Uncover Habitat Use of RedCrowned Cranes: Implications for Conservation. Current Zoology, 59, 604-617.

[41] Barter, M. (2002) Shorebirds of the Yellow Sea: Importance, Threats and Conservation Status. Wetlands International Global Series 9, International Wader Studies 12, Canberra, Wetlands International, Wageningen.

[42] Research Systems (2008) ENVI 4.5. Research Systems, Inc., Boulder.

[43] Environmental Systems Research Institute (2006) ArcGIS 9.2. ESRI, Redlands.

[44] Laba, M., Downs, R., Smith, S., Welsh, S., Neider, C., White, S., Richmond, M., Philpot, W. and Baveye, P. (2008) Mapping Invasive Wetland Plants in the Hudson River National Estuarine Research Reserve Using Quickbird Satellite Imagery. Remote Sensing of Environment, 112, 286-300. http://dx.doi.org/10.1016/j.rse.2007.05.003

[45] Zadeh, L.A. (1965) Fuzzy Sets. Information and Control, 8, 338-353. http://dx.doi.org/10.1016/S0019-9958(65)90241-X

[46] Gopal, S. and Woodcock, C. (1994) Theory and Methods for Accuracy Assessment of Thematic Maps Using FuzzySets. Photogrammetric Engineering and Remote Sensing, 60, 181-188.

[47] Boers, A.M. and Zedler, J.B. (2008) Stabilized Water Levels and Typha Invasiveness. Wetlands, 28, 676-685. http://dx.doi.org/10.1672/07-223.1 
[48] Westbrooks, R.G. (2004) New Approaches for Early Detection and Rapid Response to Invasive Plants in the United States. Weed Technology, 18, 1468-1471. http://dx.doi.org/10.1614/0890-037X(2004)018[1468:NAFEDA]2.0.CO;2

[49] Shen, Y., Yang, J., Wang, Y., Feng, N., Zhou, Q. and Zeng, H. (2008) Impact of Sediment Supply on Spartina Salt Marshes. Pedosphere, 18, 593-598. http://dx.doi.org/10.1016/S1002-0160(08)60053-3

[50] Wang, Q., Wang, C., Zhao, B., Ma, Z., Luo, Y., Chen, J. and Li, B. (2006) Effects of Growing Conditions on the Growth of and Interactions between Salt Marsh Plants: Implications for Invisibility of Habitats. Biological Invasions, 8, 1547-1560. http://dx.doi.org/10.1007/s10530-005-5846-x

[51] Bascand, L.D. (1970) The Roles of Spartina Species in New Zealand. Proceedings of the New Zealand Ecological Society, 17, 33-40.

[52] Daehler, C.C. and Strong, D.R. (1994) Variable Reproductive Output among Clones of Spartina alterniflora (Poaceae) Invading San-Francisco Bay, California-The Influence of Herbivory, Pollination, and Establishment Site. American Journal of Botany, 81, 307-313. http://dx.doi.org/10.2307/2445457

[53] Gan, X., Cai, Y., Choi, Y., Ma, Z., Chen, J. and Li, B. (2009) Potential Impacts of Invasive Spartina alterniflora on Spring Bird Communities at Chongming Dongtan, a Chinese Wetland of International Importance. Estuarine Coastal and Shelf Science, 83, 211-218. http://dx.doi.org/10.1016/j.ecss.2009.03.026

[54] Ma, Z., Gan, X., Cai, Y., Chen, J. and Li, B. (2010) Effects of Exotic Spartina alterniflora on the Habitat Patch Associations of Breeding Saltmarsh Birds at Chongming Dongtan in the Yangze River Estuary, China. Biological Invasions, 13, 1673-1686. http://dx.doi.org/10.1007/s10530-010-9924-3

[55] Daehler, C.C. (2003) Performance Comparisons of Co-Occurring Native and Alien Invasive Plants: Implications for Conservation and Restoration. Annual Review of Ecology Evolution and Systematics, 34, 183-211. http://dx.doi.org/10.1146/annurev.ecolsys.34.011802.132403

[56] Callaway, J.C. and Josselyn, M.N. (1992) The Introduction and Spread of Smooth Cordgrass (Spartina alterniflora) in South San Francisco Bay. Estuaries, 15, 218-226. http://dx.doi.org/10.2307/1352695

[57] Zhou, H., Liu, J., Zhou, J. and Qin, P. (2008) Effect of an Alien Species Spartina alterniflora Loisel on Biogeochemical Processes of Intertidal Ecosystem in the Jiangsu Coastal Region, China. Pedosphere, 18, 77-85. http://dx.doi.org/10.1016/S1002-0160(07)60105-2

[58] Hedge, P., Kriwoken, L.K. and Patten, K. (2003) A Review of Spartina Management in Washington State, US. Journal of Aquatic Plant Management, 41, 82-90.

[59] Gao, Y., Tang, L., Wang, J., Wang, C., Liang, Z., Li, B., Chen, J. and Zhao, B. (2009) Clipping at Early Florescence Is More Efficient for Controlling the Invasive Plant Spartina alterniflora. Ecology Research, 24, 1033-1041. http://dx.doi.org/10.1007/s11284-008-0577-y

[60] Aberle, B. (1990) The Biology, Control and Eradication of Introduced Spartina (Cordgrass) Worldwide and Recommendations for Its Control in Washington, Olympia, Washington. Reports to Washington State Department of Natural Resources, Olympia, Washington DC.

[61] Mendelssohn, I.A., McKee, K.L. and Patrick Jr., W.H. (1981) Oxygen Deficiency in Spartina alterniflora Roots: Metabolic Adaptation to Anoxia. Science, 214, 439-441. http://dx.doi.org/10.1126/science.214.4519.439

[62] Yuan, L. and Zhang, L. (2010) Effects of Waterlogging on the Physiology of Spartina alterniflora. Oceanologia et Limonogia Sinca, 41, 175-179.

[63] Buhle, E.R., Feist, B.E. and Hilborn, R. (2012) Population Dynamics and Control of Invasive Spartina alterniflora: Inference and Forecasting under Uncertainty. Ecological Applications, 22, 880-893.

http://dx.doi.org/10.1890/11-0593.1 